\title{
A Study on the Puns in English Advertisement from the Perspective of Relevance Theory
}

\author{
Yujie Chang
}

School of Foreign Languages, Zhengzhou University of Industrial Technology, Zhengzhou 451100, China

499716288@qq.com

Keywords: Relevance Theory, pun, English advertisement, context.

\begin{abstract}
As a vital product of the contemporary society, advertisement has drawn much attention. The advertisers pay much attention to language strategies for the sake of leaving impression on the audience within limited time and space. Among a lot of different linguistic rhetorical devices, pun is seen as the most important one. It has been many years since advertising languages were studied. Many scholars studied it from different expects. Pun has also been studied from a variety of angles. However, those studies were almost limited to its definition, features, classifications and rhetoric effects, and less attention has been paid to the application of puns in field of advertising. Thus, the purpose of the paper is to show how people understand puns in advertisements more effectively.
\end{abstract}

\section{Introduction}

\subsection{Research Background}

As an important product of contemporary economic society, advertisement has attracted a lot of attention from the audiences. As a special form of linguistic performance, the slogan has a unique style and some features. Lots of rhetorical devices are used in English advertisements, and pun is one of the most popular. Using of puns in advertisements properly can produce economic benefits and make the advertisers keep ahead in the fierce competition.

In recent many years, many scholars from domestic and overseas have studied pun from a variety of perspectives. Each study was helpful to later studies, but they seldom to reveal the cognitive system. Besides, those studies were almost limited by pun's definition, features, classifications and rhetoric effects, so less attention has been attached to the application of puns in advertisements. Thus, the present paper attempts to show how people comprehend puns in advertisements better.

\subsection{Research Purpose and Significance}

Through the study of puns in English advertisements, it is not difficult to find the application of puns in advertisements can achieve optimal relevance through different ways. A pun is concise and rich, and it also conforms to the characteristics of advertisements. This paper can not only help advertisers to understand how to apply puns to English advertisements, but also can arouse the readers' interest in puns in English advertisements and help the readers better understand the meanings of puns in English advertisement.

The present study on the puns in English advertisements is of great significance theoretically and practically. It is very necessary to analyze puns in advertising based on relevance theory, and try to find out how people can better understand the connotation of puns in advertisements. In theory, it can enhance the explanatory power of Relevance Theory. In addition, it can promote more profound study on the puns. In practice, it can offer some enlightenment for the interpretation of puns in English advertisements. It not only can help people understand the puns in advertising better and faster, but also can guide advertisers to use puns in advertising more effectively. 


\section{Literature Review}

The studies on the puns in English advertisement in China have grown vigorously for many years. Zhang Jun presented that puns in advertising not only can attract the attention of the audience, but also can enhance persuasiveness in her paper An Analysis on English Puns from the Perspective of Relevance Theory. Any forms of puns used in advertisement can make the audience understand the meanings of puns in certain context by paying extra effort, and thus stimulate shopping desire of the audience, as well as achieving the marketing purpose. In this paper On the Interpretation of Puns in English Advertisements from Relevance Theory, Chen Lina analyzed that when pun is regarded as ostensive stimulus and used in English advertisement by advertisers, how it makes the audience obtain understanding on the puns in advertisements. The analysis of the understanding process on the puns in advertisements can make the audience better understand advertising puns and make the advertisers use puns more effective. Sun Xin in his thesis An Interpretation on English Puns from the Perspective of Relevance Theory pointed out that it was necessary and effective to use relevance theory to interpret puns in English advertisements, because relevance theory provided a complete and appropriate theoretical framework for interpreting English puns.

Foreign scholars Mcquarrie and Mick discussed about the widespread application of puns in English advertisements. They thought pun as a kind of word game was applied in different contexts of advertising, which was very useful for advertisements. They proposed that a pun was not only a popular rhetoric way, but also the most complex rhetoric way. In article Guano of the Mind: Puns in Advertising, Redfern thought that a pun was a very economical as a way of Advertising. The application of a pun to advertisement could lessen the space and shorten words or sentences, so as a kind of rhetoric way, a pun could save time and labor. Sperber and Wilson, on the basis of relevance principle, put forward that advertisers intentionally made full use of the characteristics of puns and provided two or more interpretations of puns for the audience. Although the audience had to make more effort in the process of apprehending puns, this is a purpose that advertisers really wanted to achieve.

To conclude, the studies on the puns in English advertisement have gradually attracted more and more attention, and the research perspectives about the theme have become more extensive. However, because the research perspective of this subject is diversified, there are still a relatively large number of problems to be researched. Therefore, in this paper, the writer will begin a study on the puns in English advertisement from the perspective of Relevance Theory on the basis of related literature and predecessors' research experience.

\section{Relevance Theory}

Relevance Theory was formally put forward by Dan Sperber and Deidre Wilson in their book Relevance: Communication and Cognition in 1986. They thought that all Gricean maxims, including the cooperation principle itself, should be reduced to a single principle of relevance. And they gave the definition as follows: every act of ostensive communication expresses a kind of presumption according to optimal relevance. In the second edition, Sperber and Wilson indicated that in fact there are two relevance-based principles. And they rechristen this principle as Communicative Principle of Relevance, and added another one, known as Cognitive Principle of Relevance that means human's cognition tends to be geared to the maximization of relevance.

In Relevance Theory, context is also known as a contextual assumption. It includes not only communicational context and social environment, but also the encyclopedic knowledge and cognitive information. This information does not form a single context, but a series of contexts. In discourse comprehension, people select a particular context to infer information. Communication depends on whether the listener can use the right context or not. Sperber and Wilson, proposing dynamic context theory, thought that context is not static, but a kind of choice in the process of discourse understanding. Therefore, in the oriented-relevance verbal communication, the speaker always makes some assumptions or inference to the listener's cognitive ability and contextual resources. Then he chooses 
the appropriate language in the proper way to convey the message to the listener, so that the listener can use minimal effort to get the greatest contextual effect and optimal relevance.

Sperber and Wilson thought that finding the optimal relevance was the key to successful communication, any words were relevant. The process of understanding discourse is the process of searching for relevance. The optical relevance is from the best contextual effect. However, the contextual effect is not freely obtainable, and it requires people to make efforts to achieve.

\section{Puns in English Advertisement}

\subsection{Definition and Features of Puns in English Advertisement}

The definition of pun is not the same in different dictionaries. According to the explanation from The Oxford English Dictionary, pun means the use of a word in such a way as to suggest two or more meanings or different connotations, or the use of two or more words of the same or nearly the same sound with different meanings, so as to produce a humorous effect. Guo Huimin thought that pun was applied in words and made words and sentences have dual meanings in a particular situation. Chen Jiaojing pointed out that pun was not only for the use of word games, but also was a popular rhetorical device in English language. Fan Jiacai quoted Joel Sherzer's definition about puns, "pun is a kind of language skill, and a word or sentence may have a variety of unrelated explanations, so that it can bring unexpected results."

Pun uses homophony phenomenon skillfully to make some words or sentences with the same pronunciation have different meanings, and does not express the meanings directly, which is very unique. So it is said that pun is the source of wisdom. Advertisers allow the audience to see the advertisement information and make them get influenced by using pun.

Kang Canhui argued that pun has two characteristics. One is ambiguity, and the other is double contexts. Pun is full of wisdom and gives a good addition to the advertisements. Beautiful languages and artistic charm is the key to attract readers. Pun is often an optimal choice for advertising designers. Information, attention, interest, aesthetic value and memory effect reflect the quality of advertising. Good advertising can attract readers' attention and leave deep impression on the readers. Besides, Kang Canhui defined ambiguity as: a kind of language, including a word, may have two or more cognitive connotations. No matter what is the form of the language, the purpose of the speaker using double meanings is to achieve ambiguity. Therefore ambiguity is the most important and most basic characteristic of pun. The second characteristic of pun is multiple contexts. Readers can easily be attracted by the charm of this unique language phenomenon and be interested in artistic effect it conveys. Redfern put forward that one sentence can express two kinds of meaning, and this is also a sort of benefits that advertisers want to pursue Mick noted that the advertisers often encounter with some problems in the communication with readers due to the lack of trust and social cooperation, and pun is an effective way to communicate with readers. Roderick in his book Advertising, advised advertisers that it was wise to use fewer words in conveying messages to readers. Thus, using puns to make advertising language is a good choice for the advertisers.

\subsection{Classification of Puns}

\subsubsection{Homophonic Pun}

Homophonic pun means that two words have the same or similar pronunciation and spelling, but they have different meanings. Or the pronunciations of them are same, but the spelling and the meaning of them are different. In view of this, the advertisers like using homophonic puns in advertisements and make advertisements become more humors. Such advertisements can attract more attention from the audience and enhance memory of the audience for advertising.

(1) $O I C$.

This is an advertisement from a company where a kind of glasses is produced in America. The pronunciation of it is: "Oh, I see." Obviously, homophonic pun is used in the advertisement, which enhances the visual and sound effects of the advertisement. The advertisers use homophonic to emphasize OIC and express the brand. Besides, using homophonic pun can enhance the visual effect 
and attract the interest of the audience. When the audiences see the advertisement, they couldn't help reading it: "oh, I see." The three letters strengthen the sound effects and promote the audience to infer, so that the audience can find out the optimal relevance: OIC brand glasses let you see more clearly.

(2) Have a nice trip, buy-buy.

This is a popular advertisement. You can see the advertisement appears in an airport in English. At first glance, this is a polite language from the airport: "wish you a pleasant journey, goodbye!" But after a while, it's not hard to find that "buy - buy" is phonetic variants of "bye - bye". Stores in the airport say goodbye to the passengers. At the same time, it also reminds you to buy some gifts before you leave.

\subsubsection{Semantic Pun}

Semantic pun means that a word has many different meanings or the same spelling words have different meanings polysemy, which makes words or sentences in a specific environment form a pun rhetoric.

(3) A deal with us means A good deal to you.

This advertisement cleverly used the phrase "a good deal". The phrase not only refers to "a good deal", but also has the meaning of "many". Obviously, using semantic pun in advertisements can strengthen advertisements' value and achieve the purpose of marketing. Advertisers aroused the audience's interests and prompted the audience to infer dual meanings of the advertisement.

4.2.3 Grammatical Pun

Grammatical pun refers to puns caused by grammatical functions.

(4) Ask for More.

This is a cigarette advertisement of Moore. Advertisements cleverly used grammatical pun. In this sentence, "more" has dual meanings: when considered as an adverb, it means "more, much more". But when "M" is a capital letter, the word "More" becomes the brand of a kind of cigarette. Through this advertisement the advertisers show the contents of the advertisement: anything more. This arouses the audience's interest. They try to find optimal relevance along with context, and lastly realize the meaning of "More". "More" also means "one more cigarette". This process of expressing and inferring leaves a deeper impression on the audience.

\subsubsection{Idiom Pun}

Puns used in English advertisements are innumerable. Among them, some familiar idioms can be used. These idioms not only enhance the appeal of advertisements, but also show the artistic charm of advertisements. Advertisers found that idiom was closely related to the spirits of English countries, so they boldly adopted this new form of advertising.

(5) The BERD's in hand.

This is an advertisement of the European bank for reconstruction and development. BERD is abbreviation of "the bank of reconstruction and development". The advertisement cited an idiom: "a bird in hand is worth two in the bush". Advertisers use idioms to arouse the audience's interest and make the audience infer and finally realize that this "BERD" is not "bird". Here "BERD" is the term of the bank. And the implication of the advertisement is that "with the bank's loan, you will overcome difficulty and survive".

\subsubsection{Pun in Brand}

Many advertisers like using the rhetoric of pun on the brand name of commodity. Pun in brand undoubtedly can enhance people's memory on brand and strengthen publicity, so as to achieve the purpose of selling goods.

(6)The lable of achievement. The Black lable command more respect.

This is an advertisement of a kind of whisky called: "Black Lable". Lable not only means "symbol", but also refers to the brand-Black Lable. Through using puns, advertisers express the content of the advertisement and tell the audience that this wine is a sign of "success", which stimulates the audience's interest. Therefore, people can get optical relevance by inferring: Black Lable wine is a sign of success and makes you more honorable. In addition, people also think that black represents 
dignity and decency in western countries. This enhances the memory value of advertising and achieves the purpose of marketing.

\subsection{3 Functions of Puns in English Advertisement}

The ultimate aim of advertisement is to persuade customers to buy the products or services. Puns contain ambiguity and have double contexts which both make the consumers understand by making extra effort. Advertisers prefer to apply puns to advertisements because there are some reasons for the advertisers who could not abandon puns. The following are several vital functions of puns in advertisements.

\subsubsection{Providing Information}

Advertisements are used to send information about the products or services to buyers, and it informs the buyers of the features of products and the locations of sale. Whatever ways the advertisers use, they will provide some information about the product for the audience as much as possible. Pun can be regarded as a word which has two or more meanings and produces unlike associations. The form of a pun is simple, but the meanings it contains or provides are rich. Thus, using the puns in advertisements can provide rich information for the audience with simple words or sentences.

\subsubsection{Attracting Attention}

Attracting attention is the first and most important requirement for a successful advertisement. If the consumers are interested in an advertisement, then it means that the advertiser gets a better chance to impact the potential consumers and arouse their buying decision. A pun is a kind of play of words. It is really a device to draw the readers' attention. For advertisers, it is very crucial to attract the attention of readers, and the pun is one of the rhetorical devices most often used to meet certain purpose. Because puns have ambiguity, they attract attention by creating a puzzle. They arouse the audience's interest by making him think: "What on earth does that mean?" The final goal of an advertisement is not to convey a clear idea, for there are few new things to say about many products. And creating a sense of surprise is one way of attracting attention.

\subsubsection{Cutting Cost}

Since we now live in a high-speed developing society, and time means money. Time is very priceless for people. As a result, in our daily life, an advertisement will cost the advertiser a lot of money. It is impossible for both the producer and the advertiser to make a long and complex advertisement. The longer and more complex an advertisement is, and then more money they will cost. While pun possesses the advantage of being economical because of its concision, it is a kind of space-saving and labor-saving device. Besides, people can also get more information by understanding only one word or phrase. Therefore, puns are often applied to advertisements.

\subsubsection{Summary}

Punning as a rhetoric device is properly used for these functions in advertisements. These functions make advertisements more persuasive and persuade the readers to believe something and then take some actions.

\section{Relevance Theory and Puns in English Advertisement}

\subsection{Puns in Relevance Theory}

Relevance Theory provides a theoretical framework for the study on puns in English advertisements. Relevance makes readers see unique charm of advertisements. Good advertisements are usually new and unique, and they can express relevant meanings and let the readers like them. Advertising can realize the purpose of ostensive communication and implicative communication. The success of communication is to make readers grasp the information and understand the intention that the speaker wants to convey. In an advertisement, the speaker is an advertiser, and he tries to convince potential customers to buy his products. Relevance runs through the entire process of communication. Advertising producers do not communicate with customers directly, but they realize the purpose of communication by using advertisements with puns. The audiences will pay more attention to advertisements because they have made extra efforts in inferring puns and adjusting to context. In the 
process of understanding puns, the audiences will get mental and physical pleasure. At the same time, these advertisements will leave a deep impression on the audiences.

In short, as a kind of rhetorical strategy or way of sales promotion, pun successfully adopts Relevance Theory. The communicative process between advertisements and the audiences produces the effect of humor. Analyzing puns from the perspective of Relevance Theory not only can explain the communicative effect of puns in English advertising, but can help the audiences understand the meanings of puns more deeply. As a significant theory of pragmatics, Relevance Theory is a theoretical basis for language learners, and it makes us master language more purposefully, so that we can achieve cultural communication.

\subsection{Puns in English Advertisement}

Advertisers sometimes deliberately use puns in advertisements to suggest two or more interpretations. In this kind of advertising, the initial interpretation has nothing to do with promotion of products and services, and this interpretation must be negative. The purpose of using advertisements is to arouse the readers' curiosity and attract their attention. The following is an advertisement about the underground in London.

(1) Less bread. No jam.

At first glance, people immediately think of the food, because both bread and jam are an instant and inseparable food in British People's daily life. But this advertisement is about a subway, so this advertisement apparently does not tally with relevance principle. Relevance principle demands that any communicative behavior must ensure their closest correlation. After denying this understanding, the audiences will realize that the bread in spoken language refers to "money" and jam can be called "traffic jam". Then the slogan becomes: less money, no traffic jam. When the elliptical sentence is completed and the implicit meaning immediately appears: "you can save money by taking the underground of London, and it can make you far away from the hardship of traffic jam". Pun has brought two explanations literally, but finally it just wants to convey an intention. On the basis of Relevance Theory, the food and the subway have no relevance, so the reader will naturally abandon the first understanding and actively seek optimal relevance. On the basis of Relevance Theory, any communicative activities will have an expectation on relevance. Puns in advertisements can attract readers' attention because they can provide relevant cognitive context as expressive stimulation. In the process of interpreting discourse, the hearer needs to obtain new information and gets the contextual effect through a series of contextual assumptions, so as to deduce the meaning of discourse and understand the intention of the speaker.

(2) Money doesn't grow on trees. But it blossoms on our branches.

Money doesn't grow on trees, but it can blossom in the branches? The odd topic naturally allows the readers to think. Considering its context, it is an advertisement for a bank, so the readers will quickly realize that the branch should be associated with a bank here. "Branch" not only refers to the branches of trees, but also the branches of banks. The implication that the advertisement conveys is obviously "let your money in our bank branches, and you will have a good income". Once getting the right understanding, the readers will get satisfaction, and advertisements will unsurprisingly leave a profound impression on the readers. Pun can attract readers' attention because expectations of relevance make the readers firstly confused and then suddenly be enlightened.

\section{Conclusion}

The study employs Sperber and Wilson's Relevance Theory to examine pun application in English advertisements. Relevance Theory proposed by Sperber and Wilson has opened up a new perspective for the study on the puns in English and Chinese advertisements. The application of puns in advertising can achieve optimal relevance through different ways. A pun is brief and rich, and it also obeys to the characteristics of advertising. Context is very important for the interpretation of advertisements and makes the hearers achieve optimal relevance in interpreting advertisements. Some 
basic assumptions of Relevance Theory are obtained by analyzing the context of puns. Relevance Theory is a very convenient tool to analyze puns in English advertisements.

\section{References}

[1] Macquarie \& Mick, G.M. Figures of Rhetoric in Advertising Language [M]. Journal of Consumer Research, 1996.

[2] Redfern, W. Guano of the Mind: Puns in Advertising [M]. Language and Communication, 1984. [3] Sperber \&Wilson. Relevance: Communication and Cognition [M]. Oxford: Blackwell, 2006. 